\title{
Evaluation of Size of the Condyle in Vertical and Anteroposterior Skeletal Conditions with the Help of Cone-beam Computed Tomography
}

\author{
Jyotirmay ${ }^{1}$, Sanjay K Singh ${ }^{2}$, Kumar Adarsh ${ }^{3}$, Abhishek Sinha $^{4}$, Amit Kumar $^{5}$, Suprabha Sharan ${ }^{6}$
}

\begin{abstract}
Aim: Evaluation of size of the condyle in various vertical and anteroposterior skeletal conditions with the help of cone-beam computed tomography (CBCT).

Methods and materials: In this study, 266 study participants were included consisting of 112 males and 144 females. The study participants were categorized as class I when $-1^{\circ} \leq$ A point-nasion-B point angle (ANB) $<4^{\circ}$, class II when ANB $\geq 4^{\circ}$, and class III when ANB $<-1^{\circ}$. The study participants were categorized as hypodivergent when the mandibular plane (MP) $\leq 23^{\circ}$, normodivergent when $23^{\circ}<M P<30^{\circ}$, and hyperdivergent when $\mathrm{MP} \geq 30^{\circ}$. CBCT images were obtained for each subject and measurement of length, width, and height of the condyle was carried out. The data were collected and analysis of covariance test (ANCOVA) was used for statistical analysis. Statistical significance was adjusted at $p \leq 0.05$.

Results: The size of the condyle was smaller in females. The length of the condyle was similar in different anteroposterior and vertical positions with no significant difference. The width of the condyle and the height of the condyle were greatest in class III anteroposterior condition while they were lowest in class I condition. The width and height of the condyle were greatest in hypodivergent condition while they were lowest in hyperdivergent condition.

Conclusion: It was concluded that the height and width of the condyle vary considerably in different vertical and anteroposterior skeletal patterns and the size of the condyle was smaller in women as compared with men.

Clinical significance: The position of the condyle and its morphology are important features that constitute an important part of orthodontic treatment planning. The skeletal pattern of the patient has also an important effect on the diagnosis, planning of treatment, and prognosis in the orthodontic treatment.

Keywords: Anteroposterior skeletal pattern, Condyle size, Cone-beam computed tomography, Vertical skeletal pattern.

The Journal of Contemporary Dental Practice (2021): 10.5005/jp-journals-10024-3001
\end{abstract}

\section{INTRODUCTION}

The position and morphology of the condyle are an important part of orthodontic treatment planning. It has been found that the skeletal pattern has an important effect on the diagnosis, planning of treatment, and prognosis in orthodontic treatment.' Several studies have shown that there is a significant relationship between the type of malocclusion and the shape of the mandibular fossa and the condyle. The maximum amount of occlusal force and activities of muscles of mastication are also affected by the vertical condition of the face and anteroposterior skeletal condition of the face. The prevalence of internal disc derangement was higher in the study participants where the vertical condition is hyperdivergent in nature. ${ }^{2}$ In previous studies conducted utilizing lateral cephalograms and computed tomography, it has been observed that there is a significant relationship between the shape of the condyle and anteroposterior skeletal conditions. It has been also observed that the condyle is more anteriorly positioned in study participants having skeletal class III malocclusion. ${ }^{3}$ A study conducted in past by Rodrigues et al. has shown that anteroposterior position and size of the condyle are significantly related in class III skeletal malocclusion while such a significant relationship is not observed in skeletal class II and class I malocclusion. ${ }^{4}$
${ }^{1}$ Department of Orthodontics and Dentofacial Orthopaedics, Patna Dental College and Hospital, Patna, Bihar, India

${ }^{2}$ Department of Dentistry, Patna Medical College and Hospital, Patna, Bihar, India

${ }^{3}$ Department of Orthodontics and Dentofacial Orthopaedics, Dr. B. R. Ambedkar Institute of Dental Sciences and Hospital, Patna, Bihar, India

${ }^{4}$ Department of Dentistry, Patna Medical College and Hospital, Patna, Bihar, India

${ }^{5}$ Consultant Orthodontist, Patna, Bihar, India

${ }^{6}$ Private Practitioner, Patna, Bihar, India

Corresponding Author: Sanjay K Singh, Department of Dentistry, Patna Medical College and Hospital, Patna, Bihar, India, Phone: +91 8986528227, e-mail: drsanjaysortho@gmail.com

How to cite this article: Jyotirmay, Singh SK, Adarsh K, et al. Evaluation of Size of the Condyle in Vertical and Anteroposterior Skeletal Conditions with the Help of Cone-beam Computed Tomography. J Contemp Dent Pract 2021;22(2):189-193.

Source of support: Nil

Conflict of interest: None

(c) Jaypee Brothers Medical Publishers. 2021 Open Access This article is distributed under the terms of the Creative Commons Attribution 4.0 International License (https://creativecommons.org/licenses/by-nc/4.0/), which permits unrestricted use, distribution, and non-commercial reproduction in any medium, provided you give appropriate credit to the original author(s) and the source, provide a link to the Creative Commons license, and indicate if changes were made. The Creative Commons Public Domain Dedication waiver (http://creativecommons.org/publicdomain/zero/1.0/) applies to the data made available in this article, unless otherwise stated. 
For proper planning of orthodontic treatment proper analysis of disorders of the temporomandibular joint (TMJ) is very necessary. But this is a complicated process and requires detailed clinical and proper radiographic evaluation as the structure of the TMJ is very complex. Three-dimensional radiographic imaging like conebeam computed tomography (CBCT) gives good radiographic details about TMJ. It is believed worldwide that CBCT provides radiographic images with high resolution. ${ }^{5}$ The proper diagnosis of temporomandibular joint dysfunction (TMDs) is also necessary for a better quality of life in patients undergoing fixed orthodontic treatment. ${ }^{6}$

The condyle is the main site for the growth of the mandible. It undergoes several changes during the remodeling process. It plays an important role in the final dimension of the adult mandible. Therefore, the size of the condyle affects the final size of the mandible and the relationship between the mandibular and maxillary arch. In this way, the size of the condyle is an important factor in orthodontic diagnosis, treatment, and prognosis. ${ }^{7}$ Anteroposterior and vertical skeletal conditions are also important factors in orthodontic diagnosis, treatment, and prognosis. Very few studies have been conducted to evaluate the correlation between the size of the condyle and various anteroposterior and vertical skeletal conditions of the face. Therefore, this study was carried out to evaluate the correlation between the size of the condyle and different vertical and anteroposterior skeletal conditions among adult study participants with the help of CBCT.

\section{Methods and Materials}

The study was carried out at the Department of Orthodontics, Patna Dental College and Hospital, Patna. In this study, 266 study participants were included consisting of 112 males and 144 females. The patients in the age group 18-26 years were included in this study. Clearance was obtained from the ethical committee and written informed consent was obtained from all the study participants who participated in the study. The study participants with a history of systemic disease, congenital disease, previous orthodontic treatment, and head and neck surgery were excluded from the study. Besides the study participants with clinical features of temporomandibular diseases like a clicking sounds at the TMJ region, reduced mouth opening, and pain at the TMJ regions were also excluded from the study. Those study participants who were found to have anatomical abnormalities of the condyle like flattening of the condyle, agenesis of the condyle, osteophytes, etc. were also excluded from the study. CBCT imaging and lateral cephalogram of all the study participants who were included in the study was carried out. All the measurements for the size of the condyle were carried out by one observer who was completely unaware of the study design. Evaluation of lateral cephalogram of each subject was carried out. The study participants were classified into different anteroposterior conditions like class I condition, class II condition, and class III condition based on ANB angle (A pointnasion-B point angle). The study participants were categorized as class I when the condition was $-1^{\circ} \leq \mathrm{ANB}<4^{\circ}$. The study participants were categorized into class II condition when the condition was ANB $\geq 4^{\circ}$ while the study participants were categorized in class III condition when ANB $<-1^{\circ} .8$

Study participants were classified into different vertical conditions like hypodivergent, normodivergent, and hyperdivergent based on MP (mandibular plane angle) evaluated on the lateral cephalogram. The study participants were categorized as hypodivergent when the condition was MP $\leq 23^{\circ}$. The study participants were categorized as normodivergent when the condition was $23^{\circ}<\mathrm{MP}<30^{\circ}$. The study participants were categorized as hypodivergent when the condition was MP $\geq 30^{\circ} .8$

CBCT scan images were obtained for all the study participants included in the study. The CBCT machine (Vatech 3D, Korea) was the same for conducting the entire CBCT scan. The settings were adjusted as per the manufacturer's instructions. Field of view (FOV) was adjusted at $10 \times 10 \mathrm{~cm}^{2}, \mathrm{kV}$ was adjusted at $85, \mathrm{~mA}$ was adjusted at 4 , and rotation was adjusted at $360^{\circ}$. It was taken care that while obtaining a CBCT scan image, patients were in sitting position and were static in position so that their Frankfort plane was parallel with the ground.

The methods used for measurements of the size of the condyle on both right and left sides were that elaborated by Stringert and Worms and Burke et al. ${ }^{9,10}$ In this method certain anatomical landmarks were demarcated on the CВCT images and then the distances between these anatomical landmarks were measured to evaluate length, width, and the height of the condyle. For determination of the length of the condyle, the landmarks were $\mathrm{SCo}, \mathrm{ACo}$, and PCo in the sagittal section. SCo was the point at the superior most position of the condyle. ACo was the point on the anterior surface of the condyle $4 \mathrm{~mm}$ below SCo on the front side. PCo was the point at the posterior surface of the condyle $4 \mathrm{~mm}$ below the SCo. A line was drawn to connect the ACo and PCo. The measurement of this line gave the length of the condyle (Fig. 1). For measurement of the height of the condyle, a tangent was drawn through the inferior most point of the sigmoid notch in the sagittal section of CBCT. This tangent was drawn parallel with the horizontal line. The intersection point between this tangent and posterior border of ramus was demarcated. A line was drawn connecting this intersection point with the SCo. The measurement of this line gave the height of the condyle (Fig. 2). For measurement of the width of the condyle, the landmarks demarcated were MCo and LCo. MCo was the mandible pole on the medial side while LCo was the mandible pole on the lateral side. Both these landmarks were demarcated in the coronal section of $C B C T$ showing the maximum dimension of the mandible. A line was drawn to connect the MCo and LCo. The measurement of this line gave the width of the condyle in the coronal plane (Fig. 3). The condylar length, height, and width were measured using $\mathrm{CBCT}$ images by one investigator.

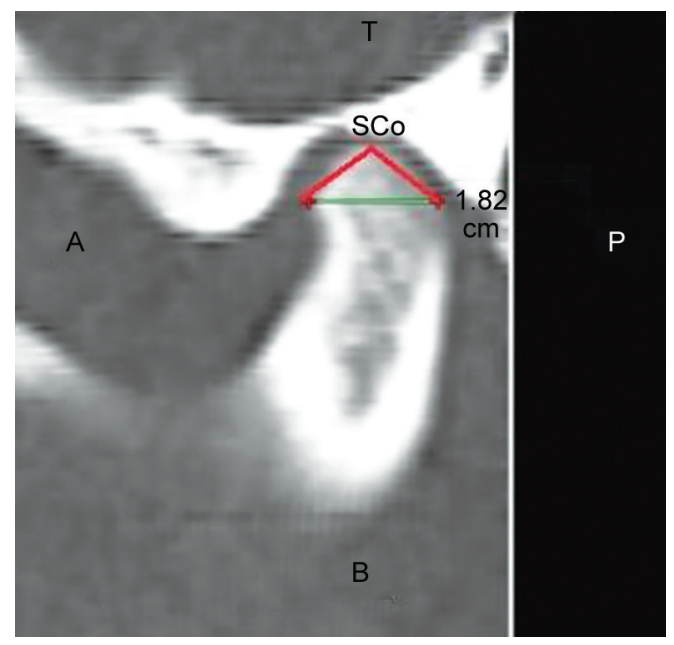

Fig. 1: $C B C T$ image showing measurement of the length of the condyle 


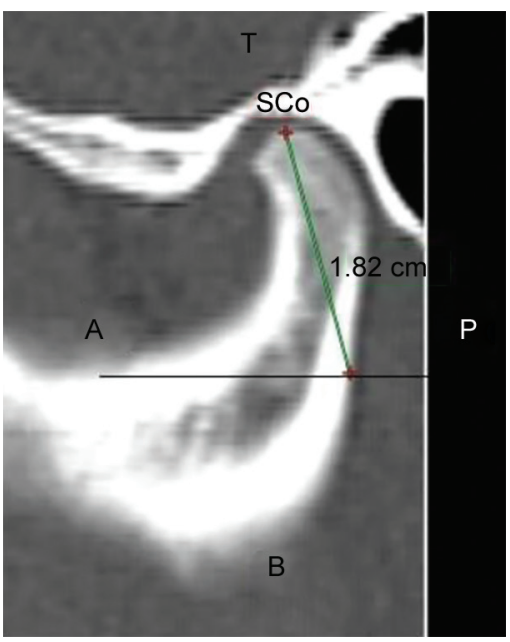

Fig. 2: $\mathrm{CBCT}$ image showing measurement of the height of the condyle

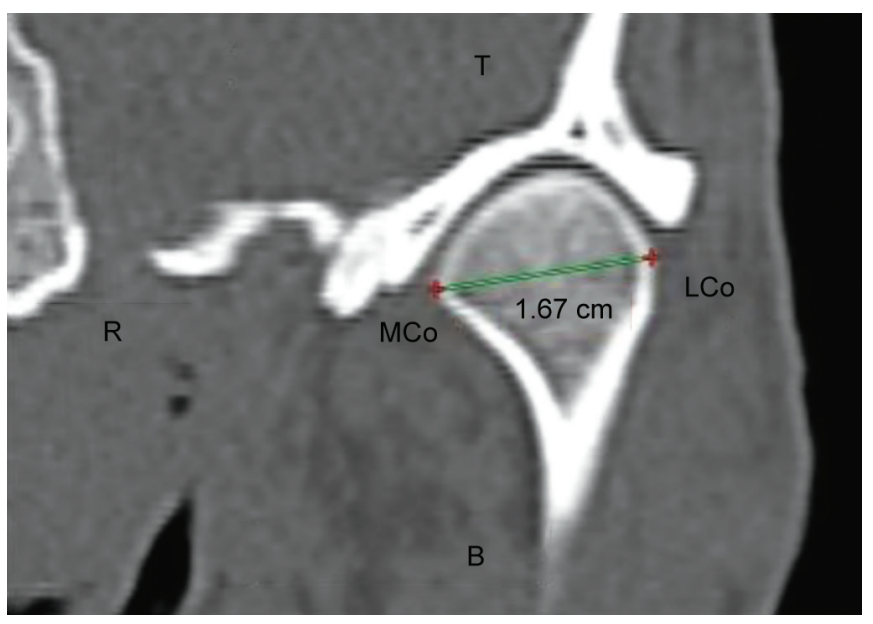

Fig. 3: $\mathrm{CBCT}$ image showing measurement of the width of the condyle

Table 1: Evaluation of size of the condyle in males and females

\begin{tabular}{|c|c|c|c|}
\hline & Males & Females & \\
\hline & Mean value $(\mathrm{mm}) \pm S E$ & Mean value $(\mathrm{mm}) \pm S E$ & $p$-value ${ }^{*}$ \\
\hline Length of condyle in left direction & $8.43 \pm 0.124$ & $7.33 \pm 0.121$ & 0.02 \\
\hline Length of condyle in right direction & $8.34 \pm 0.123$ & $7.23 \pm 0.132$ & 0.03 \\
\hline Width of condyle in left direction & $16.72 \pm 0.121$ & $15.31 \pm 0.119$ & 0.03 \\
\hline Width of condyle in right direction & $16.34 \pm 0.110$ & $15.21 \pm 0.163$ & 0.02 \\
\hline Height of condyle in left direction & $20.21 \pm 0.108$ & $19.34 \pm 0.111$ & 0.03 \\
\hline Height of condyle in right direction & $20.43 \pm 0.127$ & $19.42 \pm 0.117$ & 0.02 \\
\hline
\end{tabular}

*, Statistically significant; SE, standard error

Table 2: Evaluation of the size of the condyle in various anteroposterior skeletal conditions

\begin{tabular}{|c|c|c|c|c|}
\hline & Class / condition & Class I/ condition & Class III condition & \\
\hline & Mean value $(\mathrm{mm}) \pm S E$ & Mean value $(\mathrm{mm}) \pm S E$ & Mean value $(\mathrm{mm}) \pm S E$ & $p$-value ${ }^{*}$ \\
\hline Length of condyle in left direction & $8.31 \pm 0.212$ & $8.68 \pm 0.121$ & $8.74 \pm 0.131$ & 0.07 \\
\hline Length of condyle in right direction & $8.15 \pm 0.121$ & $8.67 \pm 0.221$ & $8.75 \pm 0.123$ & 0.08 \\
\hline Width of condyle in left direction & $15.45 \pm 0.132$ & $16.67 \pm 0.111$ & $17.34 \pm 0.141$ & 0.03 \\
\hline Width of condyle in right direction & $15.34 \pm 0.122$ & $16.37 \pm 0.132$ & $17.24 \pm 0.121$ & 0.04 \\
\hline Height of condyle in left direction & $20.21 \pm 0.131$ & $18.23 \pm 0.166$ & $23.34 \pm 0.132$ & 0.02 \\
\hline Height of condyle in right direction & $20.23 \pm 0.211$ & $19.34 \pm 0.101$ & $23.04 \pm 0.121$ & 0.03 \\
\hline
\end{tabular}

*, Statistically significant; SE, standard error

ANCOVA test, i.e., analysis of covariance was used for statistical analysis. SPSS Statistics Version 23 (IBM Corporation) was used for carrying out all statistical analyses. Statistical significance adjusted at $p \leq 0.05$.

\section{Results}

The mean age of male study participants was 23.2 years while the mean age of female study participants was 23.1 years. The study participants with class I condition were 37 males and 48 females. The study participants in the class II condition were 38 males and 50 females while the study participants in the class III condition were 37 males and 46 females. The study participants in the hypodivergent condition were 36 males and 50 females. The study participants in normodivergent condition were 38 males and 48 females while the study participants in hypodivergent condition were 38 males and 46 females.

The length, width, and height of the condyle were shorter in females as compared with the male study participants. The difference was statistically significant with $p \leq 0.05$ (Table 1). When evaluation of the size of the condyle was carried out in various anteroposterior skeletal conditions then there was no statistically significant difference in length of the condyle in class I, class II, and class III conditions with $p \geq 0.05$. The width and height of the condyle were greatest in class III condition while they were lowest in class I condition. The width and height of the condyle in class II condition were more than that of class I but less than that of class III condition. The difference was statistically significant with $p \leq 0.05$ (Table 2). When the evaluation was carried out in different 
Table 3: Evaluation of size of the condyle in various vertical skeletal conditions

\begin{tabular}{|c|c|c|c|c|}
\hline & Hyperdivergent & Normodivergent & Hypodivergent & \\
\hline & Mean value $(\mathrm{mm}) \pm S E$ & Mean value $(\mathrm{mm}) \pm S E$ & Mean value $(\mathrm{mm}) \pm S E$ & $p$-value ${ }^{*}$ \\
\hline Length of condyle in left direction & $9.34 \pm 0.231$ & $8.56 \pm 0.141$ & $8.24 \pm 0.121$ & 0.67 \\
\hline Length of condyle in right direction & $9.42 \pm 0.121$ & $8.54 \pm 0.123$ & $8.32 \pm 0.141$ & 0.78 \\
\hline Width of condyle in left direction & $15.56 \pm 0.121$ & $16.23 \pm 0.212$ & $17.32 \pm 0.132$ & 0.03 \\
\hline Width of condyle in right direction & $15.34 \pm 0.112$ & $16.91 \pm 0.312$ & $17.21 \pm 0.331$ & 0.02 \\
\hline Height of condyle in left direction & $18.21 \pm 0.111$ & $19.32 \pm 0.113$ & $20.24 \pm 0.110$ & 0.03 \\
\hline Height of condyle in right direction & $18.32 \pm 0.114$ & $19.34 \pm 0.112$ & $20.23 \pm 0.161$ & 0.04 \\
\hline
\end{tabular}

*, Statistically significant; SE, standard error

vertical skeletal conditions then there was no significant difference in length of the condyle in hypodivergent, normodivergent, and hyperdivergent conditions ( $p \geq 0.05$ ). There was a decrease in the width of the condyle and the height of the condyle while moving from hypodivergent to normodivergent to hyperdivergent conditions. The difference was statistically significant with $p \leq 0.05$ for the width of the condyle and the height of the condyle (Table 3). There was no significant difference in the size of the condyle on comparing the left and right sides.

Therefore, it was found that the size of the condyle was smaller in females. The length of the condyle was similar in different anteroposterior and vertical positions with no significant difference. The width and height of the condyle were greatest in class III anteroposterior condition while they were lowest in class I condition. The width and height of the condyle in the class II condition were greater than that class I condition while they were lower than that of the class III condition. As far as vertical conditions were concerned the width of the condyle and the height of the condyle was greatest in hypodivergent condition while they were lowest in hyperdivergent condition. In the normodivergent condition, the values were in between these two conditions. There was a significant difference in the height and width of the condyle in different vertical conditions.

\section{Discussion}

In this study size of the condyle was compared in different vertical and anteroposterior skeletal conditions using CBCT considering sex differences and it was found that the height and the width of the condyle vary considerably in different anteroposterior and vertical skeletal patterns while the size of the condyle was smaller in females as compared with males. However, there was no significant correlation between the length of the condyle and different anteroposterior and vertical conditions. Similar results were found in Japan to compare the size of the condyle among different vertical and anteroposterior skeletal conditions with the help of CBCT and found that the height and width of the condyle were significantly related with various skeletal conditions. ${ }^{11,12}$

In a study, it was found that the width of the condyle was greatest in hypodivergent skeletal condition while it was lowest in hyperdivergent vertical skeletal condition. It was found that the size of the condyle was smaller in females as compared with that of males. Similarly in the present study, it was found that the width of the condyle was greatest in hypodivergent condition and lowest in hyperdivergent condition. The size of the condyle was smaller in females in the present study also. Another important finding in a study, it was found that signs and symptoms of disorders of the temporomandibular joint were more commonly observed in female study participants as compared with that of male study participants. It was observed that the volume of the mandible was different in different sexes. ${ }^{13,14}$

The results obtained were not similar to the present study as it was observed that there was no significant difference in the condyle size in different skeletal conditions. However, it was found that the volume and surface area of the condyle was greater in class III skeletal condition as compared with class II and class I condition. ${ }^{15}$ Hayashi et al. conducted a study and found that difference was not statistically significant in the volume of mandible among different anteroposterior skeletal conditions. The results of this study were not in accordance with the present study. ${ }^{16}$ In the current study, a statistical difference in the condylar height and width was found among vertical and anteroposterior skeletal conditions. The reason for such contrasting results may be the variation in the geographical conditions in which these studies were conducted.

Malocclusion is a multifactorial phenomenon. The factors responsible for malocclusion may be a combination of both skeletal and dental conditions of the craniofacial regions. ${ }^{17,18}$ The skeletal conditions affecting the occlusion include both the anteroposterior and vertical conditions. Skeletal conditions are very important in the diagnosis, treatment, and prognosis of orthodontic treatment. Since the condyle is the main site of development of the mandible and several changes take place in the condyle during the remodeling process for the development of the mandible. Therefore, the size of the condyle plays an important role in the final dimensions of the mandible. Besides the size of the condyle also affect the relationship between the mandibular and maxillary arch. In this way, the size of the condyle plays important role in the orthodontic diagnosis, treatment planning, and prognosis., ${ }^{7,19}$ In this study correlation between the size of the condyle and different vertical and anteroposterior skeletal conditions was evaluated and found that the width and the height of the condyle vary according to various skeletal conditions and gender. The clinical implications of this study can be explained by the fact that width and the height of the condyle vary according to anteroposterior and vertical skeletal conditions and gender, therefore, it is necessary to identify such variations as well as abnormalities, especially during orthodontic treatment and orthognathic surgery.

This was the first study in our country to evaluate the correlation between the size of the condyle and various skeletal conditions. Another new thing in this study was that CBCT was used for the analysis of the size of the condyle. It has been observed that conventional radiographs used in orthodontic treatment like lateral cephalograms and orthopantomography 
are mainly two-dimensional imaging. The condyle is a threedimensional structure, therefore these conventional methods are not adequate for evaluation of the condyle size. ${ }^{20,21}$ On the other hand $C B C T$ is three-dimensional imaging having better details. So $\mathrm{CBCT}$ is a better imaging technique for analysis of the size of the condyle. Moreover, there is no image magnification and image distortion in CBCT as reported in other conventional radiographic techniques like lateral cephalograms and orthopantomograph. CBCT provides high-resolution images with good accuracy in measurements. ${ }^{22}$ Therefore, CBCT was used for radiographic analysis in this study. Measurements of the length, width, and height of the condyle in this study were evaluated. This method has been previously used in several studies conducted over Asian populations. $^{23}$

The limitations of this study were high radiation exposure due to the use of $C B C T$. Besides the $C B C T$ examination is very expensive due to which the number of study participants included in this study was limited in number. The sample size of the study should have been larger. Other limitations of the study were that confounding factors like age, trauma, and endocrine disorders were not included in the study.

\section{ConcLusion}

It can be concluded that the height and width of the condyle vary considerably in different anteroposterior and vertical skeletal patterns while the size of the condyle is smaller in females as compared with males. However, there is no significant correlation between the length of the condyle and different anteroposterior and vertical conditions. More studies with a large sample size should be conducted further for better results.

\section{References}

1. Bou Assi S, Macari A, Hanna A, et al. Cephalometric evaluation of maxillary incisors inclination, facial, and growth axes in different vertical and sagittal patterns: an original study. J Int Soc Prev Community Dent 2020;10(3):292-299. DOI: 10.4103/jispcd. JISPCD_60_20.

2. Ponces MJ, Tavares JP, Lopes JD, et al. Comparison of condylar displacement between three biotypological facial groups by using mounted models and a mandibular position indicator. Korean J Orthod 2014;44(6):312-319. DOI: 10.4041/kjod.2014.44.6.312.

3. Vitral RWF, Telles CdeS, Fraga MR, et al. Computed tomography evaluation of temporomandibular joint alterations in patients with class II division 1 subdivision malocclusions: condyle-fossa relationship. Am J Orthod Dentofacial Orthop 2004;126(1):48-52. DOI: 10.1016/j.ajodo.2003.06.012.

4. Rodrigues AF, Fraga MR, Vitral RW. Computed tomography evaluation of the temporomandibular joint in Class I malocclusion patients: condylar symmetry and condyle-fossa relationship. Am J Orthod Dentofacial Orthop 2009;136(2):192-198. DOI: 10.1016/j. ajodo.2007.07.032.

5. Schudy FF. Treatment of adult midline deviation by condylar repositioning. J Clin Orthod 1996;30(6):343-347.

6. Alqefari J, Albelaihi R, Elmoazen R, et al. Three-dimensional assessment of the oral health-related quality of life undergoing fixed orthodontic therapy. J Int Soc Prev Community Dent 2019;9(1):72-76. DOI: 10.4103/jispcd.JISPCD_350_18.

7. Tecco $S$, Saccucci $M$, Nucera R, et al. Condylar volume and surface in Caucasian young adult subjects. BMC Med Imaging 2010;10:28. DOI: 10.1186/1471-2342-10-28.
8. Custodio W, Gomes SG, Faot F, et al. Occlusal force, electromyographic activity of masticatory muscles and mandibular flexure of study participants with different facial types. J Appl Oral Sci 2011;19(4):343349. DOI: 10.1590/S1678-77572011005000008.

9. Stringert HG, Worms FW. Variations in skeletal and dental patterns in patients with structural and functional alterations of the temporomandibular joint: a preliminary report. Am J Orthod 1986;89(4):285-297. DOI: 10.1016/0002-9416(86)90050-3.

10. Burke G, Major P, Glover K, et al. Correlations between condylar characteristics and facial morphology in Class II preadolescent patients. Am J Orthod Dentofacial Orthop 1998;114(3):328-336. DOI: 10.1016/s0889-5406(98)70216-1.

11. Cohlmia JT, Ghosh J, Sinha PK, et al. Tomographic assessment of temporomandibular joints in patients with malocclusion. Angle Orthod 1996;66(1):27-35. DOI: 10.1043/0003-3219(1996) 066<0027:TAOTJI>2.3.CO;2.

12. Gianelly AA, Petras JC, Boffa J. Condylar position and Class II deepbite, no-overjet malocclusions. Am J Orthod Dentofacial Orthop 1989;96(5):428-432. DOI: 10.1016/0889-5406(89)90328-4.

13. Naeije M, Te Veldhuis AH, Te Veldhuis EC, et al. Disc displacement within the human temporomandibular joint: a systematic review of a 'noisy annoyance'. J Oral Rehabil 2013;40(2):139-158. DOI: 10.1111/ joor.12016.

14. Dalili Z, Khaki N, Kia SJ, et al. Assessing joint space and condylar position in the people with normal function of temporomandibular joint with cone-beam computed tomography. Dent Res J (Isfahan) 2012;9(5):607-612. DOI: 10.4103/1735-3327.104881.

15. Tsiklakis K, Syriopoulos K, Stamatakis HC. Radiographic examination of the temporomandibular joint using cone beam computed tomography. Dentomaxillofac Radiol 2004;33(3):196-201. DOI: $10.1259 / \mathrm{dmfr} / 27403192$.

16. Hayashi T, Ito J, Koyama J, et al. Detectability of anterior displacement of the articular disk in the temporomandibular joint on helical computed tomography: the value of open mouth position. Oral Surg Oral Med Oral Pathol Oral Radiol Endod 1999;88(1):106-111. DOI: 10.1016/s1079-2104(99)70202-7.

17. Ikeda K, Kawamura A. Assessment of optimal condylar position with limited cone-beam computed tomography. Am J Orthod Dentofacial Orthop 2009;135(4):495-501. DOI: 10.1016/j.ajodo.2007.05.021.

18. Seren $\mathrm{E}, \mathrm{Akan} \mathrm{H}$, Toller MO, et al. An evaluation of the condylar position of the temporomandibular joint by computerized tomography in Class III malocclusions: a preliminary study. Am J Orthod Dentofacial Orthop 1994;105(5):483-488. DOI: 10.1016/S0889-5406(94)70009-5.

19. Vitral RW, Telles CdeS. Computed tomography evaluation of temporomandibular joint alterations in class II Division 1 subdivision patients: condylar symmetry. Am J Orthod Dentofacial Orthop 2002;121(4):369-375. DOI: 10.1067/mod.2002.121664.

20. Hilgers ML, Scarfe WC, Scheetz JP, et al. Accuracy of linear temporomandibular joint measurements with cone beam computed tomography and digital cephalometric radiography. Am J Orthod Dentofacial Orthop 2005;128(6):803-811. DOI: 10.1016/j. ajodo.2005.08.034.

21. Oliveira SR, Oliveira RDS, Rodrigues ED, et al. Accuracy of panoramic radiography for degenerative changes of the temporomandibular joint. J Int Soc Prev Community Dent 2020;10(1):96-100. DOI: 10.4103/ jispcd.JISPCD_411_19.

22. Katsavrias EG. Morphology of the temporomandibular joint in study participants with Class II Division 2 malocclusions. Am J Orthod Dentofacial Orthop 2006;129(4):470-478. DOI: 10.1016/j. ajodo.2005.01.018.

23. Rodrigues AF, Fraga MR, Vitral RW. Computed tomography evaluation of the temporomandibular joint in Class II Division 1 and Class III malocclusion patients: condylar symmetry and condyle-fossa relationship. Am J Orthod Dentofacial Orthop 2009;136(2):199-206. DOI: 10.1016/j.ajodo.2007.07.033. 